\title{
Bionomic aspects of Lutzomyia evansi and Lutzomyia longipalpis, proven vectors of Leishmania infantum in an endemic area of non-ulcerative cutaneous leishmaniasis in Honduras
}

\author{
Ángel Mejía', Gabriela Matamoros ${ }^{1}$, Gustavo Fontecha ${ }^{2^{*}}$ (1) and Wilfredo Sosa-Ochoa ${ }^{2}$
}

\begin{abstract}
Background: Some Lutzomyia species are the vectors of human leishmaniasis in the Americas. Visceral and cutaneous leishmaniasis are both endemic in the Pacific region of Honduras, but the non-ulcerative form is the more frequent clinical manifestation in this region, where Lutzomyia longipalpis is the most abundant and the only incriminated vector. Taxonomic identification and distribution studies of sand flies are important to understand the epidemiology and to control these neglected tropical diseases.

Results: Here, we identified more than 13,000 Lutzomyia specimens captured in Isla del Tigre, Honduras, through a classical morphological approach. The two most common species were Lutzomyia evansi and Lu. longipalpis, and this is the first report of three Lutzomyia species on this island. The blood meal source was successfully identified for five sand fly species. A barcode analysis using the cox 1 mitochondrial marker proved to be effective in discriminating between species and seems to be a valuable tool for future epidemiological studies including a wider geographical area.

Conclusion: This study updates the diversity and blood meal sources of Lutzomyia species in an island endemic for non-ulcerative cutaneous leishmaniasis in the Pacific region of Honduras, and determines the effectiveness of the barcoding approach to discriminate species, as a complementary tool to classical morphology.
\end{abstract}

Keywords: Non-ulcerative cutaneous leishmaniasis, Visceral leishmaniasis, Barcoding

\section{Background}

Leishmaniasis is a complex of human and zoonotic diseases caused by parasites of the genus Leishmania. In the American continent Leishmania parasites are transmitted to their hosts through the bite of hematophagous insects of the genus Lutzomyia [1]. To date, leishmaniases are considered as one of the main "neglected tropical diseases" in the world and are a major obstacle for the development of countries like Honduras because of its strong association with poverty and healthy life years lost from disability [2-4].

\footnotetext{
* Correspondence: gustavo.fontecha@unah.edu.hn

${ }^{2}$ Microbiology Research Institute, Universidad Nacional Autónoma de

Honduras, Tegucigalpa, Honduras

Full list of author information is available at the end of the article
}

According to the National Surveillance Laboratory and the Panamerican Health Organization Office in Honduras, the number of human infections caused by Leishmania parasites in Honduras during 2015 was 2054, mostly as cutaneous presentations [5] (Table 1).

In Honduras there are four known manifestations of human leishmaniasis, and they are classified according to clinical signs, geographical distribution, parasite species, and vector species in each area. Non-ulcerative cutaneous leishmaniasis (NUCL, also called atypical cutaneous leishmaniasis [6]), cutaneous (CL) and visceral leishmaniasis (VL) are endemic in Southern Honduras (Pacific Region) due to specific eco-epidemiological characteristics $[7,8]$. The ulcerative disease contributed to $50.6 \%$ of total national cases in 2015, while the non-ulcerative cutaneous 
Table 1 Number (n) of Leishmania infections reported in: Honduras (HN), the Pacific region of the country comprising Choluteca and Valle departments (PR), and in Isla del Tigre (IT), from 2009 to 2015. The four clinical forms are reported separately

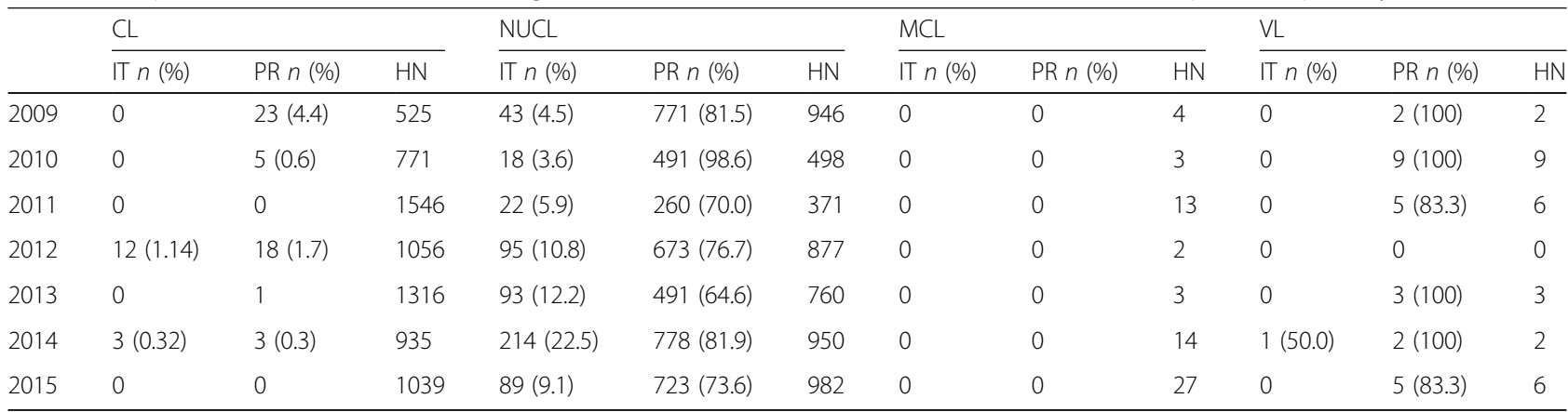

Abbreviations: $C L$ cutaneous, NUCL non-ulcerative, $M C L$ muco-cutaneous, $V L$ visceral

form represented $47.8 \%$ of the parasite infections. The Pacific region of Honduras (including Choluteca and Valle departments or provinces) reported $723(73.6 \%)$ cases of NUCL in 2015, and Isla del Tigre alone (belonging to Valle department) contributed with 89 (9\%) of the total amount of cases. The parasite responsible for both clinical manifestations (VL and NUCL) seems to be Leishmania infantum (syn. L. chagasi) [6, 8].

In the Neotropics there are nearly 500 species of Lutzomyia identified according to morphological characters [9], and at least 30 of which have been described as Leishmania vectors [10]. In Honduras, 31 Lutzomyia species have been reported and 12 show anthropophilic behavior [11]. Lutzomyia longipalpis is considered vector of only Leishmania (L.) infantum and not of other parasite species. Although Leishmania species causing cutaneous leishmaniases have been identified by molecular methods in $\mathrm{Lu}$. longipalpis, those findings have no epidemiological significance [12]. Lutzomyia longipalpis is also the best described species in Honduras and is the only one from which $L$. infantum strains have been isolated. For these reasons $\mathrm{Lu}$. longipalpis is considered as the main vector of VL in southern Honduras [4, 5]. However, other sand fly species have been highlighted as permissive vectors of the parasite in the Americas such as Lu. evansi, Lu. fischeri and $L u$. migonei, among others $[13,14]$.

On the other hand, studies on the feeding habits of Leishmania vectors is as important as the description of the circulating species in a geographical area, because that knowledge contributes to identifying potential reservoirs, to understanding their role in the maintenance of insect populations in a locality, levels of anthropophilia, as well as in defining the zoonotic or anthroponotic cycles of the disease $[15,16]$.

Lutzomyia specimens are classically identified upon morphological internal characters such as spermatheca and genitalia, among other structures, although there are several disadvantages with this approach. For example, this method requires a vast experience and technical training and is laborious and time-consuming; also it is not always possible to have good quality specimens because of damages during capture, transport or mounting [17]. In addition, some populations of sand flies show some degree of phenotypic plasticity [18], or cryptic species may be co-existing in the same location [19, 20]. The development of molecular tools based on DNA sequences, allows to complement taxonomic identification based solely on morphology. One of the most commonly used markers for the identification of sand flies is the gene cytochrome $c$ oxidase subunit 1 ( $\operatorname{cox} 1$ ), because of its high level of conservation [21, 22]. Therefore, the aim of the present study was to identify the species of Lutzomyia on a Mesoamerican Pacific island where leishmaniasis is endemic, using morphological and molecular methods, as well as to determine the blood meal source of these sand flies.

\section{Methods}

Area of study and collection of phlebotomine sand flies

The capture of phlebotomine sand flies was carried out in 4 villages (Ceibita, Caracol, Islitas, and Las Pelonas) of an island called Isla del Tigre, in the Pacific region of Honduras. This island was selected for this study due to the endemicity of human leishmaniasis, registering 214/ $950(22.5 \%)$ of national NUCL cases in 2014, and 89/982 (9.1\%) in 2015 (Fig. 1 and Table 1). The island is located in the Gulf of Fonseca $\left(13.2^{\circ} \mathrm{N}\right.$ and $\left.87.6^{\circ} \mathrm{W}\right)$, and has a maximum height of $783 \mathrm{~m}$ above sea level (masl) (Fig. 2). Insects were captured using CDC light traps without chemical attractant [23] in 13 collection points between August 2012 and March 2013 during one week of each month. Traps were installed in an extra-, intra- and peri-domiciliary fashion.

The first collection points were houses with the presence of domestic animals. Two traps were installed there (one intra-domiciliary and one peri-domiciliary). Peri-domiciliary traps were placed at sites of rest from domestic animals or next to the latrines. The traps were placed at a minimum distance of 25 masl. Between them in the mountain, located at the center of the island. Three 


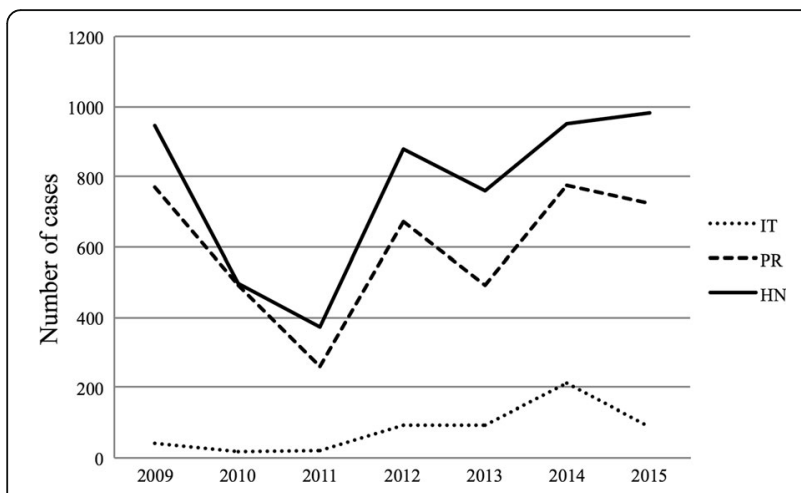

Fig. 1 Number of human leishmaniasis cases in Honduras (HN), the Pacific Region of Honduras (PR), and Isla del Tigre (IT), from 2009 to 2015

traps were placed in extra-domiciliary environments, with little or no anthropogenic intervention (crops, mountain trails, etc.). The first trap was placed $100 \mathrm{~m}$ away from the peri-domicile, and the second and third traps were placed at $100 \mathrm{~m}$ away from each other.

Ceibita village (3 collection points) is located at the northern end of the island, and was the village with the largest number of houses. Its main economic activities are subsistence agriculture and animal breeding. Two of three points were houses, and the third point (with the higher altitude) was placed in a semi-wooded environment near a field of corn of moderate extension. Caracol village (3 collection points) is located at the northwestern end of the island. Its main activities are fishing, animal breeding, and subsistence agriculture with small family gardens. Two collection sites included one house each, and the third point (extra-domiciliary) at a higher altitude was placed in a pigsty that supplies pork products to the local population. Islitas village (4 collection points) is located at the southeastern end of the island. This village has fewer houses, and most of them were located on the side of the road that surrounds the island. Its population is dedicated to animal breeding, hunting wild animals, and timber extraction. The first point evaluated at this location was a house, and the remaining 3 points were extradomiciliary into the wild up in the mountain environment. Las Pelonas village (3 collection points) is located at the northeastern end of the island. Economic activities focus on fishing, agriculture and breeding of pigs, poultry and cattle on a small scale. Lands are flatter and closer to the coast compared to the other 3 communities.

Collected insects were preserved in absolute ethanol and transported to the laboratory in Tegucigalpa, the capital city. Specimens of the genus Lutzomyia were separated from other insects. Females and males were classified through visualization of genital structures [11].

\section{Taxonomic identification of Lutzomyia species}

Ethanol-preserved specimens were hydrated in $1 \times$ PBS for $30 \mathrm{~min}$ and then cleared with $10 \% \mathrm{KOH}$ for $2 \mathrm{~h}$ and $1 \times$ PBS for $30 \mathrm{~min}$. Subsequently, the cleared specimens were mounted in permanent microscope slides with Hoyer's medium. Identification of specimens was based

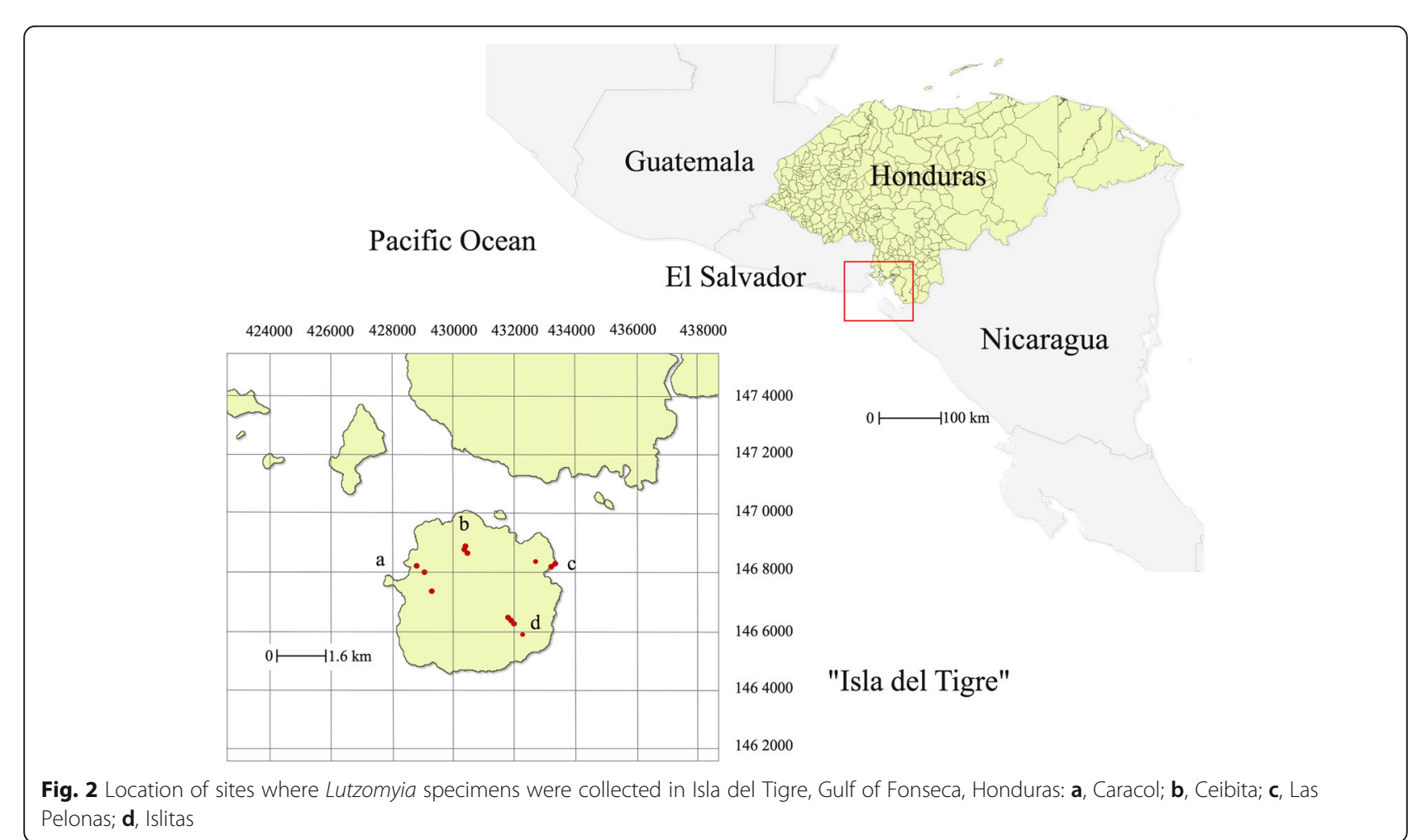


on taxonomic morphology of ascoids, wing venation, thorax coloration, the spermathecae and cibarium of the females, and the genitalia of males [11].

\section{Identification of blood meal sources}

DNA extraction was carried out from females of the genus Lutzomyia engorged with blood (with or without eggs). Specimens were dissected, identified, and pooled with other 3 individuals of the same species from the same capture site in vials with $25 \mu$ lof $5 \%$ Chelex $^{\circ} 100$ (Bio-Rad Lab Inc., Hercules, California, USA).

Sand fly pools were macerated and vortexed for $20 \mathrm{~s}$, followed by a brief centrifugation and incubation at $97{ }^{\circ} \mathrm{C}$ for $30 \mathrm{~min}$. The pools were centrifuged at $13,000 \times \mathrm{rpm}$ for $10 \mathrm{~min}$, and the supernatant was transferred to sterile vials and stored at $-20{ }^{\circ} \mathrm{C}[24]$.

In order to identify the source of the blood intake of the sand flies, four specific PCR reactions were separately performed for dog, chicken, pig, and human, as described by Pizarro et al. [15]. Short interspersed nuclear elements (SINEs) were the target for non-human species, while an Alu element-based; a long interspersed element (LINE) was amplified for detection of human DNA.

\section{Imaging and tissue lysis for barcode analysis}

Twenty-one specimens belonging to seven species of the genus Lutzomyia were processed according to the DNA barcoding workflow. This procedure includes imaging, tissue sub-sampling, tissue lysis, DNA extraction, PCR amplification and sequencing of the cox 1 marker. Specimens were imaged using the Leica Application Suite (LAS). These 21 ethanol preserved insects were analyzed for DNA barcoding in 2016 and were previously identified by conventional microscopic methods during 2013. The images used for barcoding purposes were not intended to identify the insects.

Due to the small size of the specimens, sub-sampling was not performed; instead, the entire organism was processed into plate-wells containing $30 \mu \mathrm{l}$ of $95 \%$ ethanol. Plates were centrifuged at $1000 \times g$ for $30 \mathrm{~s}$ and incubated for $2 \mathrm{~h}$ at $56{ }^{\circ} \mathrm{C}$ in order to evaporate the ethanol. For each well, $50 \mu \mathrm{l}$ of lysis buffer $(100 \mathrm{mM} \mathrm{NaCl}, 50 \mathrm{mM}$ Tris$\mathrm{HCl}, \mathrm{pH}$ 8.0, 10 mM EDTA, pH 8.0 and 0.5\% SDS, and Proteinase $\mathrm{K}$ ) were added. The plates were incubated at $56^{\circ} \mathrm{C}$ overnight.

\section{DNA extraction}

One hundred microliters of the previous binding mix were added to each well. One hundred and eighty microliters of lysate were transferred into the wells of a glass fiber plate (Pall corp., NY, USA), placed on top of a clean square-well block for binding and washing steps. The plate assemble was centrifuged at $5000 \times g$ for $5 \mathrm{~min}$ in order to bind DNA to the glass fiber membrane. Two washing steps were performed, using $180 \mu \mathrm{l}$ of protein wash buffer (binding buffer and 96\% ethanol), and $750 \mu \mathrm{l}$ of wash buffer (96\% ethanol, $50 \mathrm{mM} \mathrm{NaCl}$, $10 \mathrm{mM}$ Tris- $\mathrm{HCl} \mathrm{pH} \mathrm{7.4,} 50 \mathrm{mM}$ EDTA pH 8.0). The plate was air-dried and stored at $56{ }^{\circ} \mathrm{C}$ for $30 \mathrm{~min}$. Forty microlitres of a warmed elution buffer (10 mM TrisHCL, pH 8.0) were dispensed directly into the membrane in each well of the glass fiber plate and incubated at room temperature for $1 \mathrm{~min}$. The plate was assembled with a DNA Eppendorf plate and centrifuged at $5000 \times g$ for $5 \mathrm{~min}$ to collect the DNA. DNA was stored at $4{ }^{\circ} \mathrm{C}$ until further use.

\section{PCR amplification and sequencing}

The PCR reaction mix included $10 \%$ trehalose, $\mathrm{dd}_{2} \mathrm{O}$, 10× PCR buffer for Platinum Taq DNA polymerase (Invitrogen, Carlsbad, California, USA), $50 \mathrm{mM} \mathrm{MgCl}_{2}$, $10 \mu \mathrm{M}$ of each primer: ZplankF1t1 (5'-TGT AAA ACG ACG GCC AGT TCT ASW AAT CAT AAR GAT ATT GG-3'), ZplankR1t1 (5'-CAG GAA ACA GCT ATG ACT TCA GGR TGR CCR AAR AAT CA-3'), $10 \mathrm{mM}$ dNTPs, Platinum Taq polymerase $(5 \mathrm{U} / \mu \mathrm{l}) ; 2.5 \mu \mathrm{l}$ of DNA was added for a total volume of $12.5 \mu \mathrm{l}$.

PCR conditions were as follows: an initial step at $94{ }^{\circ} \mathrm{C}$ for $1 \mathrm{~min}$ followed by 5 cycles of $94{ }^{\circ} \mathrm{C}$ for $40 \mathrm{~s}, 45^{\circ} \mathrm{C}$ for $40 \mathrm{~s}$ and $72{ }^{\circ} \mathrm{C}$ for $1 \mathrm{~min}$. Thereafter, 35 cycles of $94{ }^{\circ} \mathrm{C}$ and $51{ }^{\circ} \mathrm{C}$ for $40 \mathrm{~s}$ and $72{ }^{\circ} \mathrm{C}$ for $1 \mathrm{~min}$ and a final extension of $72{ }^{\circ} \mathrm{C}$ for 5 min were run. Subsequently, an E-gel 2\% agarose (Invitrogen) was performed to confirm the amplification. PCR products were diluted in $25 \mu \mathrm{l}$ of $\mathrm{ddH}_{2} \mathrm{O}$ for clean-up with magnetic beads. Cycle sequencing was performed by adding $5 \mu \mathrm{l}$ of $10 \%$ trehalose, $2 \mu \mathrm{l}$ of Big Dye ${ }^{\oplus} 1.87 \mu \mathrm{l}$ of $5 \times$ sequencing buffer $(400 \mathrm{mM}$ Tris- $\mathrm{HCl} \mathrm{pH}$ 9.0, $10 \mathrm{mM} \mathrm{MgCl} 2,0.87 \mu \mathrm{l}$ of $\mathrm{ddH}_{2} \mathrm{O}, 1 \mu \mathrm{l}$ of $10 \mu \mathrm{M}$ of each primer ZplankF1t1/ZplankR1t1 and $1.2 \mu \mathrm{l}$ of PCR product. The sequencing program was: 1 cycle at $96{ }^{\circ} \mathrm{C}$ for $2 \mathrm{~min}, 30$ cycles of $96{ }^{\circ} \mathrm{C}$ for $30 \mathrm{~s}$, $55{ }^{\circ} \mathrm{C}$ for $15 \mathrm{~s}$ and $60{ }^{\circ} \mathrm{C}$ for $4 \mathrm{~min}$. Subsequently the plates were submitted for sequencing with M13F and M13R primers to the Canadian Centre for DNA Barcoding $(\mathrm{CCDB})$.

Sequences were edited using the CodonCode software (CodonCode Corp., Centerville, MA, USA) and compared against the DNA barcode library (http://www. boldsystems.org) to infer specimens' identification. The higher match, sequences overlap (nt), and match process ID was recorded.

A neighbor-joining tree was built through the Geneious $^{\oplus}$ v.9.1.7 software based on 13 sequences of local specimens and 137 sequences from the BOLD system representing 74 Lutzomyia species. All individuals were aligned using the Geneious alignment software including a 529 bp fragment of the cox 1 gene. Distances were 
computed using the Tamura-Nei model and Bootstrap values from 10,000 replicates. The percentage of identical sites and the pairwise percentage identity was calculated within and between species.

\section{Results}

\section{Identification of Lutzomyia species}

A total of 13,248 specimens belonging to the genus Lutzomyia were collected. Seventy-eight percent were female. Ten species were identified through morphological characters (Fig. 3). Sixty-four (4.83\%) specimens could not be identified due to deterioration during storage and transport and were recorded as Lutzomyia spp. The most abundant species was $L u$. evansi followed by $L u$. longipalpis (Table 2). This is the first report of three Lutzomyia species in Isla del Tigre (Lu. evansi, Lu. cayennensis and Lu. panamensis). Lutzomyia cayennensis cayennensis is the only subspecies reported in Honduras for the Lu. cayennensis complex [11]; however we do not have enough evidence to demonstrate that our specimens belong to this subspecies.

According to the location of the traps, the extradomiciliary ecotope showed a higher capture rate of sand flies (79.66\%), followed by the peri-domiciliary $(12.34 \%)$ and the intra-domiciliary ecotopes (8\%). The most frequent species in the extra-domiciliary ecotope was $L u$. evansi, while $L u$. longipalpis was most frequent in the peri-domicile setting (data not shown). Although the analysis of species diversity reveals that Islitas, is the location with greater specific richness, the four localities are very similar to each other in terms of species composition, which defines them as relatively homogeneous communities. In terms of the number of collected specimens, Ceibita contributed nearly $75 \%$ of all individuals, and $86 \%$ of $L u$. evansi specimens. The extra-domiciliary ecotope showed most of individuals of $L u$. evansi $[n=8779$ $(89.8 \%)]$, while the intra-, and the peri-domicile revealed 414 (4.2\%) and $587(6 \%)$, respectively.
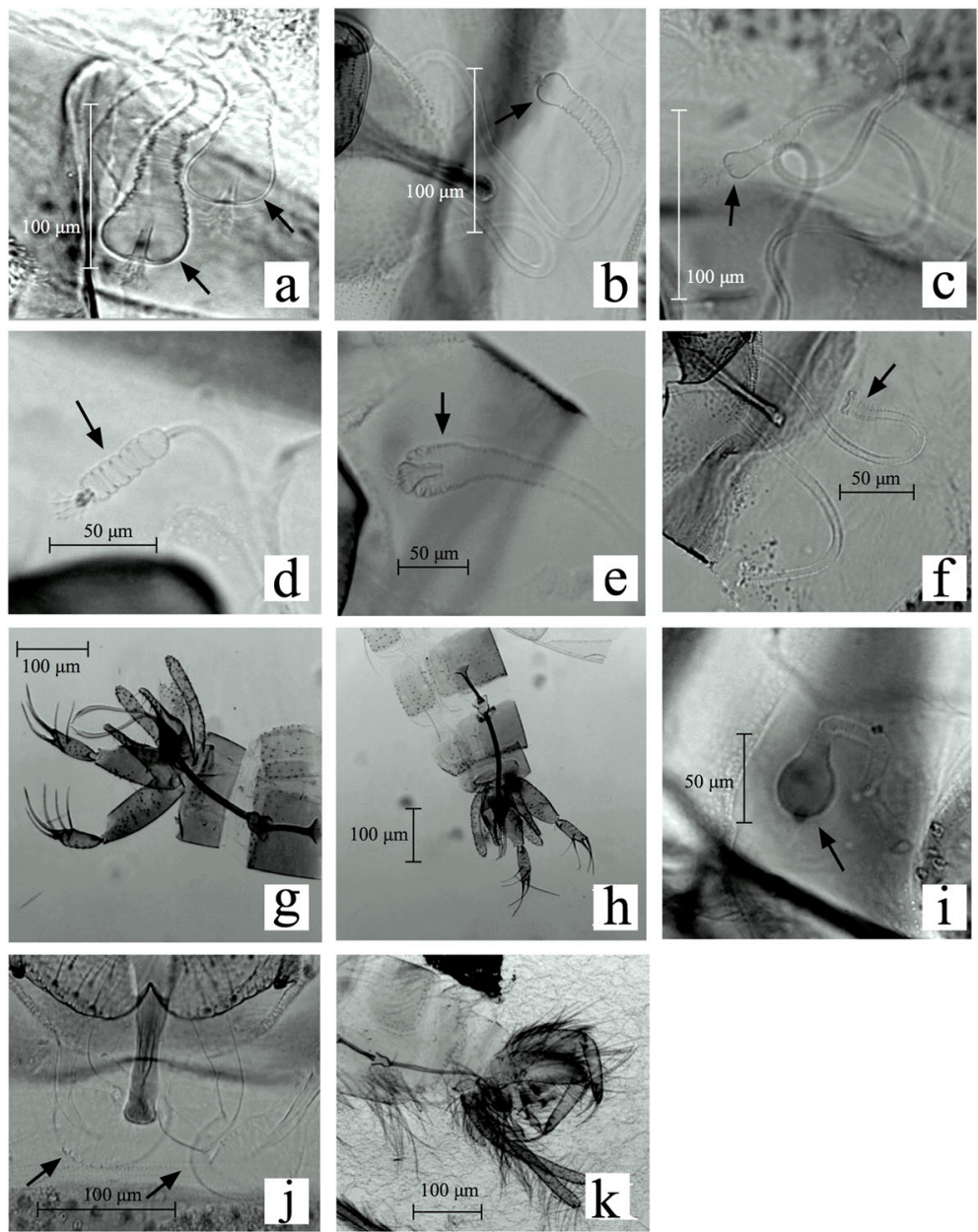

Fig. 3 Genital structures of Lutzomyia specimens from Isla del Tigre, Honduras. a Lu. chiapanensis (female). b Lu. cruciata (female). c Lu. gomezi (female). $\mathbf{d}$ Lu. longipalpis (female). e Lu. evansi (female). $\mathbf{f} L$ u. cruciata (female). $\mathbf{g} L$ L. sanguinaria (male). $\mathbf{h}$ Lu. trapidoi (male). i Lu. cayennensis (female). $\mathbf{j}$ Lu. zeledoni (female). $\mathbf{k}$ Lu. panamensis (male) 
Table 2 Number of Lutzomyia spp. specimens captured in Isla del Tigre, Honduras, classified according to sex and location

\begin{tabular}{|c|c|c|c|c|c|c|c|c|c|}
\hline \multirow[t]{2}{*}{ Lutzomyia spp./Location } & \multicolumn{2}{|c|}{ Islitas } & \multicolumn{2}{|c|}{ Ceibita } & \multicolumn{2}{|c|}{ Caracol } & \multicolumn{2}{|c|}{ Las Pelonas } & \multirow[t]{2}{*}{ Total (\%) } \\
\hline & $\bar{M}$ & $\mathrm{~F}$ & $M$ & $\mathrm{~F}$ & $\mathrm{M}$ & $\mathrm{F}$ & $M$ & $\mathrm{~F}$ & \\
\hline Lu. evansi & 107 & 261 & 460 & 7933 & 194 & 636 & 50 & 139 & $9780(73.82)$ \\
\hline Lu. longipalpis & 52 & 20 & 807 & 508 & 151 & 43 & 593 & 97 & $2271(17.14)$ \\
\hline Lu. gomezi & 6 & 23 & 8 & 33 & 50 & 151 & 8 & 70 & $349(2.63)$ \\
\hline Lu. cruciata & 26 & 37 & 40 & 41 & 55 & 117 & 11 & 25 & $350(2.64)$ \\
\hline Lu. chiapanensis & 3 & 10 & 2 & 22 & 4 & 24 & 32 & 92 & $189(1.42)$ \\
\hline Lu. sanguinaria & 2 & 0 & 22 & 0 & 32 & 0 & 116 & 0 & $172(1.29)$ \\
\hline Lu. zeledoni & 2 & 15 & 1 & 16 & 2 & 24 & 0 & 8 & $68(0.51)$ \\
\hline Lu. cayennensis & 0 & 1 & 0 & 0 & 0 & 0 & 0 & 2 & $3(0.02)$ \\
\hline Lu. trapidoi & 0 & 0 & 1 & 0 & 0 & 0 & 0 & 0 & $1(0.00)$ \\
\hline Lu. panamensis & 1 & 0 & 0 & 0 & 0 & 0 & 0 & 0 & $1(0.0)$ \\
\hline Lutzomyia sp. & 4 & 1 & 16 & 23 & 4 & 6 & 7 & 3 & $64(4.83)$ \\
\hline Subtotal & 203 & 368 & 1357 & 8576 & 492 & 1001 & 817 & 434 & \\
\hline Total n (\%) & \multicolumn{2}{|c|}{$571(4.31)$} & \multicolumn{2}{|c|}{9933 (74.97) } & \multicolumn{2}{|c|}{$1493(11.26)$} & \multicolumn{2}{|c|}{1251 (9.44) } & $13,248(100.00)$ \\
\hline
\end{tabular}

Abbreviations: $F$ female, $M$ male

\section{Identification of blood meal sources}

We found that six species harbored blood and it was possible to identify the blood meal source for five species (Lu. longipalpis, Lu. cruciata, Lu. evansi, Lu. gomezi and Lu. chiapanensis) (Table 3). All exhibited a zoophilic feeding behavior involving at least the use of one animal as a food source. The most frequent food source was pig (Sus scrofa), followed by dog (Canis familiaris), chicken (Gallus gallus), and human (Homo sapiens). Lu. longipalpis and $L u$. cruciata were the only two species with anthropophilic behavior. It was not possible to determine the blood meal source of $L u$. zeledoni. The total of the tested specimens were fed on a single animal source. No mixed blood meals were detected.

\section{Barcode analysis}

A fragment of the mitochondrial $\operatorname{cox} 1$ gene was sequenced from 21 specimens morphologically classified into 7 Lutzomyia species. Only a few specimens were selected for molecular analysis because most of the insects were permanently mounted in Hoyer's medium.
The cox1 sequence length was 622 bp by direct sequencing. Barcoding could not be performed to three of eleven species (Lu. sanguinaria, Lu. trapidoi and Lu. panamensis) because all the individuals from these species were permanently mounted for taxonomic identification four years ago. Only 13 out of 21 specimens were sequenced with enough quality to allow subsequent analysis (Table 4). Each species was analyzed using 1-3 specimens. Sequences from the 13 collected specimens showed an average A $+\mathrm{T}$ bias (66.7\%) relative to the $\mathrm{C}+\mathrm{G}$ content. Sequences and trace files are available in the BOLD project named: "Identification of Lutzomyia sp. recovered at Amapala Honduras [HNLUZ]".

The DNA barcode analysis enabled us to correctly identify 3 Lutzomyia species (Lu. longipalpis, Lu. evansi and $L u$. gomezi) as determined from the morphological identifications (Table 4). Sequences contained an average of $66.7 \%$ of $\mathrm{A}+\mathrm{T}$ pairs for all codons. The remaining 4 species (Lu. cruciata, Lu. zeledoni, Lu. chiapanensis, and Lu. cayennensis) showed low percentage matches with specimens of the family Psychodidae or with some unidentified species of the genus Lutzomyia.

Table 3 Blood meal of Lutzomyia species

\begin{tabular}{llllll}
\hline Lutzomyia spp. & Homo sapiens & Canis familiaris & Sus scrofa & Gallus gallus & Total $n(\%)$ \\
\hline Lu. longipalpis & 1 & 1 & 8 & 1 & - \\
Lu. gomezi & - & - & 7 & - & $7(9.21)$ \\
Lu. cruciata & 1 & 1 & - & - & $2(2.63)$ \\
Lu. chiapanensis & - & - & 1 & 8 & $1(1.31)$ \\
Lu. evansi & - & 15 & 32 & - & - \\
Lu. zeledoni & - & - & - & $9(11.84)$ & $75(72.36)$ \\
Total $(\%)$ & $2(2.63)$ & $17(22.36)$ & & & $76(100)$ \\
\hline
\end{tabular}


Table 4 Comparison of the species-level identifications of collected Lutzomyia specimens with the identifications as determined by DNA barcoding

\begin{tabular}{|c|c|c|c|c|c|}
\hline Phenotypic identification & BOLD Sample ID & BOLD higher match & $\%$ Highest match & Overlap (nt) & Match process ID \\
\hline Lu. longipalpis & HNLUZ004-17 & Lu. longipalpis & 99.03 & 609 & MEXSM003-12 \\
\hline Lu. longipalpis & HNLUZ005-17 & Lu. longipalpis & 98.71 & 609 & MEXSM003-12 \\
\hline Lu. evansi & HNLUZ001-17 & Lu. evansi & 93.98 & 594 & GBMIN23074-13 \\
\hline Lu. gomezi & HNLUZ008-17 & Lu. gomezi & 99.03 & 558 & GBPSY020-14 \\
\hline Lu. gomezi & HNLUZ010-17 & Lu. gomezi & 99.19 & 561 & GBPSY020-14 \\
\hline Lu. gomezi & HNLUZ012-17 & Lu. gomezi & 99.03 & 558 & GBPSY020-14 \\
\hline Lu. cruciata & HNLUZ014-17 & Lutzomyia sp. & 88.83 & 571 & None \\
\hline Lu. zeledoni & HNLUZ019-17 & Psychodidae & 98.29 & 609 & None \\
\hline Lu. zeledoni & HNLUZ020-17 & Psychodidae & 98.29 & 609 & None \\
\hline Lu. zeledoni & HNLUZ022-17 & Psychodidae & 98.10 & 609 & None \\
\hline Lu. chiapanensis & HNLUZ015-17 & Psychodidae & 91.36 & 609 & None \\
\hline Lu. cayennensis & HNLUZ024-17 & Phytoliriomyza melampyga & 91.10 & 609 & None \\
\hline
\end{tabular}

The mean interspecific nucleotide divergence was $28.4 \%$ with a pairwise percentage identity of $88.1 \%$ for a 529 bp sequence. The intraspecific nucleotide divergence ranged from $0.2 \%$ (Lu. zeledoni) to $0.6 \%$ ( $L u$. gomezi), with a pairwise percentage identity of $99.6-99.9 \%$.

When the sequences obtained in this study were analyzed along with 150 BINs available in the BOLD system for the genus Lutzomyia, the NJ tree revealed that $L u$. evansi, Lu. longipalpis, and $L u$. gomezi grouped with specimens of these species (Fig. 4); Lu. cayennensis formed a distinct but neighbour clade to other $L u$. cayennensis specimens. However, Lu. zeledoni and Lu. cruciata did not group with any other specimens of these two species. Two different species (Lu. chiapanensis and Lu. cayennensis) grouped closely in a single branch due to a high interspecific pairwise identity (99.2\%). The dendrogram also shows two clearly differentiated clades for $\mathrm{Lu}$. longipalpis. The first clade includes 6 specimens (BINs: GBPSY305-14GBPSY308-14, MEXSM002-12-MEXSM003-12) isolated from Colombia and Mexico, together with the two specimens of Honduras, while the second clade included four other specimens from Colombia (BINs: GBMIN23018, -23019, -23051, -23052).

\section{Discussion}

This study investigated the diversity of species of the genus Lutzomyia, vector of leishmaniasis in the Americas, on a highly endemic island for non-ulcerative cutaneous leishmaniasis (NUCL). During the decade of the 1990s some investigations were carried out in this geographical region of Honduras which (i) incriminated Lu. longipalpis as the vector of Leishmania infantum [7, 8]; (ii) demonstrated the predominance of Lu. longipalpis in the island; and (iii) described its behaviour [25]. Our findings were intended to provide an update on the current distribution of Leishmania vectors in the Pacific region of Honduras, plus the detection of its blood meal sources, and the use of a barcoding approach for species identification.

A large number of specimens of the genus Lutzomyia were collected and classified into ten species. Lutzomyia longipalpis has historically been considered the most common and relevant species in Leishmania transmission in the Pacific region of Honduras [25], and is the only species in which natural infections have been reported $[7,8]$.

This finding is consistent with Raymond et al. [26] who reported Lu. longipalpis and $L u$. evansi as the two most common species in the Pacific region of Nicaragua, with similar ecological characteristics as those of the Honduran Pacific. There are at least three reasons that could justify the predominance of $L u$. evansi in this study: (i) natural changes in the population dynamics of the insect; (ii) the longer capture time of this study (9 months) when compared to captures made over a few days in previous reports; and (iii) the procedure to collect sand flies also in the extra-domicile instead of the peri-domicile (edge effect) [25]. Although natural infections of the parasite in $L u$. evansi have not been demonstrated in Honduras, its potential role in the transmission of leishmaniasis cannot be ruled out, as reported for other American countries [13]. As a consequence, it would be interesting to carry out further studies to demonstrate the presence of the parasite in this phlebotomine. Taking into consideration the extradomiciliary predominance shown by $L u$. evansi, in contrast to the peri-domiciliary behavior of $\mathrm{Lu}$. longipalpis, distinct transmission cycles of $L$. infantum for each species could be proposed. For example, Leishmania infections occurring in the agricultural working areas could be attributed to $L u$. evansi, while infections around the houses could be mostly produced by $\mathrm{Lu}$. longipalpis. However, these hypotheses will 


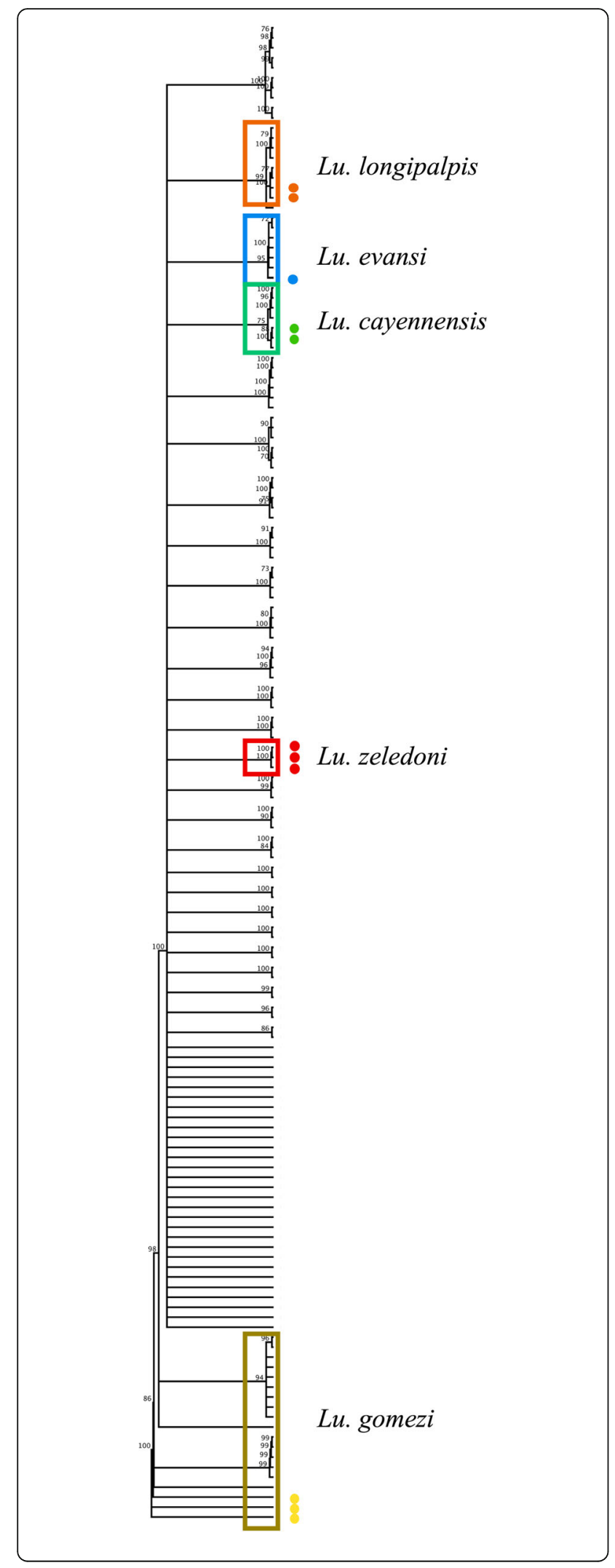

Fig. 4 Neighbor-joining tree inferred from the cox 1 gene of Lutzomyia spp. Bootstrap values from 10,000 replicates are shown.

The distances were computed using the Tamura-Nei model. Isolates from this study are shown with color dots

require further studies. A second hypothesis suggests that Lu. evansi could be maintaining the sylvatic cycle of the disease, and this could be also proven in the future through the blood identification of sylvatic animals in this sand fly species.

This is also the first report of one Lutzomyia species in Isla del Tigre which has not been incriminated in the transmission of the parasite ( $L u$. cayennensis). Two other species observed here were $L u$. gomezi and $L u$. panamensis, vectors of $L$. braziliensis and L. panamensis in the Americas $[27,28]$, but this would have no epidemiological relevance due to lack of transmission of these parasites species in the Pacific region of Honduras, although they may transmit other Leishmania species.

Despite the low dispersal abilities of Lutzomyia (e.g. $500 \mathrm{~m}$ for Lu. longipalpis) [29], the observed homogeneity in the distribution of the sand fly species in the island could be due to the small size of the territory $\left(75.2 \mathrm{~km}^{2}\right)$ and to the absence of natural or climatic barriers that could structure fragmented populations. Perhaps expanding the area of study to continental soil could evidence some level of population structure in Lutzomyia species. Despite this relative species homogeneity, the 13 collection points showed some interesting differences in the number of collected specimens.

Notoriously, Ceibita was the village with the highest number of sand flies collected (75\%) (Table 2). Perhaps the more intensive human intervention of the soil and a more abundant agricultural work are responsible for creating the conditions for the development of the life-cycle of those insects (e.g. soil modification, irrigation of crops with presence of moisture even in dry seasons, the presence of domestic and wild animals seeking food in crop fields, the presence of organic matter, shading of backyards, debris and other factors). A remarkable fact is that $86 \%$ of the catches of Lu. evansi occurred at the extra domiciliary point of collection at Ceibita. This large population caught could be attributed to an edge effect in this area, where humans are continuously penetrating the forest.

Caracol was the second village with the highest numbers of collected sand flies, and the extra-domicile was the largest contributor of the 3 collection sites. The large number of pigs in the area could be the main explanation for this result. 63.15\% (Table 3) of the engorged blood belonged to pigs, which is consistent with this hypothesis and suggests that this mammal may be a key element for the maintenance of the insect populations in extra- and peri-domiciliary ecotopes. Las Pelonas occupied the third 
place regarding the number of specimens collected. The highest number of insects was obtained in the peridomicile of a house located next to the beach, with flat and sandy soils, and close to a small piggery and a chicken coop. Likewise, the presence of domestic animals such as pigs, chickens and dogs would allow the presence of the insects in peri-domiciliary and intra-domiciliary environments. Traps located at Islitas revealed the lowest number of specimens. Fewer animals around the houses could have reduced the food sources available for the sand flies in comparison with the other three villages, with a greater presence of pets and wild animals.

This study also investigated the blood meal sources of the sand flies from Isla del Tigre. Only Lu. longipalpis and Lu. cruciata showed an anthropophilic behavior. This finding is in agreement with previous reports of authors from Brazil and Mexico [30-32] and reaffirms the potential role of $\mathrm{Lu}$. longipalpis in the transmission of visceral leishmaniasis. Five out of six Lutzomyia species revealed to be engorged with animal blood. The most frequent source of blood meal was pig, followed by dog.

Due to cultural habits of animal breeding in this region, pigs live very close to the humans and their houses. This habit is relevant in the context of this study, since $L u$. evansi have been proven to feed on pigs [33]. For this reason these animals could be considered as potential reservoirs of the parasite. The dog has been defined as the main reservoir of $L$. infantum, both in Honduras and in the Americas [7, 34-36], therefore our finding supports its leading role in establishing the domiciliary cycle of leishmaniasis on the island. Although chickens are refractory to Leishmania infections, their presence in the peridomicile is undoubtedly a risk factor that favors the presence and maintenance of sand flies in the human habitat [37, 38]. With respect to the large population of $L u$. evansi captured in Ceibita, it would be interesting to conduct further studies of other potential food sources among sylvatic animals, such as Didelphis marsupalis and small rodents [39, 40]. The source of the blood meal of $L u$. zeledoni was not identified, suggesting a different food source to the four analyzed in this study, such as armadillos [41], horses, rats, cats [42], or cows [43], among others.

Thirteen specimens belonging to seven morphologically identified Lutzomyia species were DNA barcoded in this study. This approach proved to be useful for correctly identifying three Lutzomyia species. However, four of seven species could not be identified based only on genetic divergences when their sequences were queried against public databases of the BOLD system or NCBI. This could be due to the lack of BINs or accession numbers for these species in the BOLD system and the NCBI databases, respectively. This result confirms that $\operatorname{cox} 1$ is a useful molecular marker to identify species when there are enough records in the databases $[17,44,45]$, but when there are only a few sequences available, the use of other molecular markers such as ribosomal ITS spacers or nad1 (nicotinamide adenine dinucleotide dehydrogenase 1), together with conventional taxonomy remains fundamental to report new species within a geographical region [19, 46, 47].

Sequences from the 13 collected specimens showed an average $\mathrm{A}+\mathrm{T}$ bias $(66.7 \%)$ relative to the $\mathrm{C}+\mathrm{G}$ content similar to the expected range for sand flies $[48,49]$. The variability between species (12-18\%) was similar to that reported in other studies conducted with sand flies from the Americas. Nzelu et al. [17] reported a range from 8.39 to $19.08 \%$ when 19 species from Peru were analyzed, and Contreras et al. [48] found a mean variation of $19 \%$ among 26 species collected from Colombia. However, intraspecific variability was less than $1 \%$, which can be attributed to the low number of specimens sequenced from each species in this study (max. 3). Nevertheless it seems there is no overlap between inter- and intraspecific divergences supporting the barcoding gap that allows to assign taxonomic status to our specimens [50].

The neighbor-joining tree showed distinctively clustered sequences from local specimens of $L u$. longipalpis and $L u$. evansi together with specimens of the same species from other regions of the continent (Fig. 4). However, Lu. longipalpis seemed to be grouped into two different clusters. The first cluster included the specimens from Honduras, four sequences from Colombia and two from Mexico, and the second cluster comprised four specimens from Colombia. This separation in two haplotypes will require further studies with more specimens collected from more localities in the Mesoamerican region in order to assess the existence of more than one genetic population or even cryptic species within the Lu. longipalpis complex, as suggested by other authors from Brazil [51-53]. The relationships visualized in the dendrogram between sequences from this study of $\mathrm{Lu}$. gomezi and accessions from Colombia and Panama indicate that these species are identifiable by this molecular marker. However this is not the case for Lu. cayennensis, which clustered with sequences of unidentified species of the genus Lutzomyia from Colombia, and are separated of other sequences of $L u$. cayennensis. This may be due to the diversity of the cayennensis complex including eight subspecies [27]. The sequences of Lu. zeledoni, Lu. cruciata and $L u$. chiapanensis did not cluster with any accession due to lack of previous records in the databases.

\section{Conclusions}

In conclusion, our findings updated the diversity of Lutzomyia species in an island endemic for human leishmaniasis in the Pacific region of Honduras, and provided information on the blood meal sources of these vectors. This study also showed the effectiveness of the barcoding approach to discriminate species, as a 
complementary tool to morphology-based identification. Further investigations with a larger number of specimens collected from a wider geographical area would improve the knowledge regarding the distribution of Leishmania vectors in Mesoamerica.

\author{
Abbreviations \\ BIN: barcode Index Number; BOLD: Barcode of Life Data Systems; \\ CCDB: Canadian Centre for DNA Barcoding; cox1: cytochrome c oxidase \\ subunit 1 gene; LINE: long interspersed element; PCR: polymerase chain \\ reaction; SINEs: short interspersed nuclear elements
}

\section{Acknowledgements}

We would like to thank Davide Paiva for proofreading; to Dr Concepción Zuniga, Head of the Control Program of Chagas and Leishmania; and the personnel of the Sanitary Region of Valle. We also thank Dr Rosa Mejía from $\mathrm{PAHO}$ for providing the national statistics of leishmaniasis in Honduras, and Dr Fredy Galvis from USP Brazil for revising the manuscript.

\section{Funding}

This study was financially supported by the Research Directorate of the National Autonomous University of Honduras (DICYP-UNAH). Molecular analyses were performed at the Centre for Biodiversity Genomics, Biodiversity Institute of Ontario, University of Guelph, as part of the Canada-Honduras professional training program, under the Canada Americas Trade-Related Technical Assistance Program (CATRTA) Sub-project ENV13-2016, a Program funded by Global Affairs Canada and managed by The Conference Board of Canada.

\section{Availability of data and materials}

The DNA sequences during the current study are available in the BOLD system under the project named: Identification of Lutzomyia sp. recovered at Amapala Honduras [HNLUZ] repository, (http://www.boldsystems.org). Specimens of Lutzomyia analysed during the current study are available from the corresponding author upon reasonable request.

\section{Authors' contributions}

AM and WS collected and identified the specimens. AM and WS performed the blood meal source analyses. GF and GM performed the DNA analyses. GF was a major contributor in writing the manuscript. All authors read and approved the final manuscript.

\section{Ethics approval and consent to participate}

Not applicable.

\section{Consent for publication}

Not applicable.

\section{Competing interests}

The authors declare that they have no competing interests.

\section{Publisher's Note}

Springer Nature remains neutral with regard to jurisdictional claims in published maps and institutional affiliations.

\section{Author details \\ ${ }^{1}$ Microbiology School, Universidad Nacional Autónoma de Honduras, Tegucigalpa, Honduras. ${ }^{2}$ Microbiology Research Institute, Universidad Nacional Autónoma de Honduras, Tegucigalpa, Honduras.}

Received: 9 May 2017 Accepted: 25 December 2017

Published online: 05 January 2018

\section{References}

1. Maroli M, Feliciangeli MD, Bichaud L, Charrel RN, Gradoni L. Phlebotomine sandflies and the spreading of leishmaniases and other diseases of public health concern. Med Vet Entomol. 2013;27(2):123-47.

2. Hotez PJ, Remme JH, Buss P, Alleyne G, Morel C, Breman JG. Combating tropical infectious diseases: report of the disease control priorities in developing countries project. Clin Infect Dis. 2004;38(6):871-8.
3. Alvar J, Yactayo S, Bern C. Leishmaniasis and poverty. Trends Parasitol. 2006;22(12):552-7.

4. Hotez PJ, Woc-Colburn L, Bottazzi ME. Neglected tropical diseases in central America and Panama: review of their prevalence, populations at risk and impact on regional development. Int J Parasitol. 2014;44(9):597-603.

5. WHO: Leishmaniasis: worldwide epidemiological and drug access update. http://www.who.int/leishmaniasis/burden/Country_profiles/en/. Accessed April 62017.

6. Campos-Ponce M, Ponce C, Ponce E, Maingon RD. Leishmania chagasi/infantum: further investigations on Leishmania tropisms in atypical cutaneous and visceral leishmaniasis foci in central America. Exp Parasitol. 2005;109(4):209-19.

7. Ponce C, Ponce E, Morrison A, Cruz A, Kreutzer R, McMahon-Pratt D, et al. Leishmania donovani chagasi: new clinical variant of cutaneous leishmaniasis in Honduras. Lancet. 1991;337(8733):67-70.

8. Noyes H, Chance M, Ponce C, Ponce E, Maingon R. Leishmania chagasi: genotypically similar parasites from Honduras cause both visceral and cutaneous leishmaniasis in humans. Exp Parasitol. 1997;85(3):264-73.

9. Martins AVWP, Falcão AL. American sand flies (Diptera: Psychodidae, Phlebotominae). Rio de Janeiro: Academia Brasileira de Ciencias; 1978.

10. Beati L, Caceres AG, Lee JA, Munstermann LE. Systematic relationships among Lutzomyia sand flies (Diptera: Psychodidae) of Peru and Colombia based on the analysis of $12 \mathrm{~S}$ and $28 \mathrm{~S}$ ribosomal DNA sequences. Int J Parasitol. 2004;34(2):225-34.

11. Young DGDM. Guide to the identification and geographic distribution of Lutzomyia sand flies in Mexico, the West Indies, central and South America (Diptera: Psychodidae). Memoirs Am Ent Inst. 1994;54:1-1881.

12. Savani ES, Nunes VL, Galati EA, Castilho TM, Zampieri RA, Floeter-Winter LM. The finding of Lutzomyia almerioi and Lutzomyia longipalpis naturally infected by Leishmania spp. in a cutaneous and canine visceral leishmaniases focus in Serra da Bodoquena, Brazil. Vet Parasitol. 2009;160(1-2):18-24.

13. Montoya-Lerma J, Cadena H, Oviedo M, Ready PD, Barazarte R, Travi BL, et al. Comparative vectorial efficiency of Lutzomyia evansi and Lu. longipalpis for transmitting Leishmania chagasi. Acta Trop. 2003;85(1):19-29.

14. Galvis-Ovallos F, da Silva MD, Bispo GB, de Oliveira AG, Neto JR, Malafronte RD, et al. Canine visceral leishmaniasis in the metropolitan area of Sao Paulo: Pintomyia fischeri as potential vector of Leishmania infantum. Parasite. 2017;24:2.

15. Pizarro JC, Stevens LA. New method for forensic DNA analysis of the blood meal in chagas disease vectors demonstrated using Triatoma infestans from Chuquisaca, Bolivia. PLoS One. 2008;3(10):e3585.

16. Sant'Anna MR, Jones NG, Hindley JA, Mendes-Sousa AF, Dillon RJ, Cavalcante RR, et al. Blood meal identification and parasite detection in laboratory-fed and field-captured Lutzomyia longipalpis by PCR using FTA databasing paper. Acta Trop. 2008;107(3):230-7.

17. Nzelu CO, Caceres AG, Arrunategui-Jimenez MJ, Lanas-Rosas MF, YanezTrujillano HH, Luna-Caipo DV, et al. DNA barcoding for identification of sand fly species (Diptera: Psychodidae) from leishmaniasis-endemic areas of Peru. Acta Trop. 2015;145:45-51.

18. Florin DA, Lawyer P, Rowton E, Schultz G, Wilkerson R, Davies SJ, et al. Morphological anomalies in two Lutzomyia (Psathyromyia) shannoni (Diptera: Psychodidae: Phlebotominae) specimens collected from fort Rucker, Alabama, and Fort Campbell, Kentucky. J Med Entomol. 2010;47(5):952-6.

19. Cohnstaedt LW, Beati L, Caceres AG, Ferro C, Munstermann LE. Phylogenetics of the phlebotomine sand fly group Verrucarum (Diptera: Psychodidae: Lutzomyia). Am J Trop Med Hyg. 2011;84(6):913-22.

20. Rangel EF, Lainson R, Souza AA, Ready P, Azevedo AC. Variation between geographical populations of Lutzomyia (Nyssomyia) whitmani (Antunes \& Coutinho, 1939) sensu lato (Diptera:Psychodidae:Phlebotominae) in Brazil. Mem Inst Oswaldo Cruz. 1996;91(1):43-50.

21. Romero-Ricardo L, Lastre-Meza N, Perez-Doria A, Bejarano EEDNA. Barcoding to identify species of phlebotomine sand fly (Diptera: Psychodidae) in the mixed leishmaniasis focus of the Colombian Caribbean. Acta Trop. 2016;159:125-31.

22. Scarpassa VM, Alencar RB. Molecular taxonomy of the two Leishmania vectors Lutzomyia umbratilis and Lutzomyia anduzei (Diptera: Psychodidae) from the Brazilian Amazon. Parasit Vectors. 2013;6:258.

23. Sudia WD, Chamberlain RW. Battery-operated light trap, an improved model. By W. D. Sudia and R. W. Chamberlain, 1962. J Am Mosq Control Assoc. 1988;4(4):536-8.

24. Jorquera A, Gonzalez R, Marchan-Marcano E, Oviedo M, Matos M. MultiplexPCR For detection of natural Leishmania infection in Lutzomyia spp. captured in an endemic region for cutaneous leishmaniasis in state of Sucre, Venezuela. Mem Inst Oswaldo Cruz 2005;100(1):45-48. 
25. Carrasco J, Morrison A, Ponce C. Behaviour of Lutzomyia longipalpis in an area of southern Honduras endemic for visceral/atypical cutaneous leishmaniasis. Ann Trop Med Parasitol. 1998;92(8):869-76.

26. Raymond RW, McHugh CP, Kerr SF. Sand flies of Nicaragua: a checklist and reports of new collections. Mem Inst Oswaldo Cruz. 2010;105(7):889-94.

27. Young DGDM. Guide to the identification and geographic distribution of Lutzomyia sand flies in Mexico, the West Indies, central in South America (Diptera: Psychodidade). Mem Am Entomol Inst. 1994;54:1-881.

28. Lainson RSJ. Topley \& Wilson's Microbiology \& Microbial Infections, Parasitology. In: New World Leishmaniases. 10th ed. London: ASM Press; 2005 .

29. Alexander JB. Dispersal of phlebotomine sand flies (Diptera: Psychodidae) in a Colombian coffee plantation. J Med Entomol. 1987;24(5):552-8.

30. Michalsky EM, Franca-Silva JC, Barata RA, Lara e Silva Fde O, Loureiro AM, Fortes-Dias CL, et al. Phlebotominae distribution in Janauba, an area of transmission for visceral leishmaniasis in Brazil. Mem Inst Oswaldo Cruz. 2009;104(1):56-61.

31. de Oliveira AG, Marassa AM, Consales CA, Dorval ME, Fernandes CE, de Oliveira GR, et al. Observations on the feeding habits of Lutzomyia longipalpis (Lutz \& Neiva, 1912) (Diptera: Psychodidae: Phlebotominae) in Campo Grande, an endemic area of visceral leishmaniasis in Mato Grosso do Sul. Brazil Acta Trop. 2008;107(3):238-41.

32. Rebollar-Tellez EA, Reyes-Villanueva F, Fernandez-Salas I, Andrade-Narvaez FJ. Population dynamics and biting rhythm of the anthropophilic sandfly Lutzomyia cruciata (Diptera: Psychodidae) in southeast, Mexico. Rev Inst Med Trop Sao Paulo. 1996;38(1):29-33.

33. Paternina LE, Verbel-Vergara D, Romero-Ricardo L, Perez-Doria A, PaterninaGomez M, Martinez L, et al. Evidence for anthropophily in five species of phlebotomine sand flies (Diptera: Psychodidae) from northern Colombia, revealed by molecular identification of bloodmeals. Acta Trop. 2016;153:86-92.

34. World Health Organization. Control of leishmaniasis: report of a meeting of the WHO expert committee of the control of leishmaniases. Geneva: World Health Organization; 2010.

35. Saridomichelakis MN, Koutinas AF. Cutaneous involvement in canine leishmaniosis due to Leishmania infantum (syn. L. chagasi). Vet Dermatol. 2014;25(2):61-71. e22

36. Laurenti MD, Rossi CN, da Matta VL, Tomokane TY, Corbett CE, Secundino $\mathrm{NF}$, et al. Asymptomatic dogs are highly competent to transmit Leishmania (Leishmania) infantum chagasi to the natural vector. Vet Parasitol. 2013;196(3-4):296-300.

37. Tanure A, Peixoto JC, Afonso MM, Duarte R, Pinheiro Ada C, Coelho SV, et al. Identification of sandflies (Diptera: Psychodidae: Phlebotominae) blood meals in an endemic leishmaniasis area in Brazil. Rev Inst Med Trop Sao Paulo. 2015;57(4):321-4.

38. Alexander B, de Carvalho RL, McCallum H, Pereira MH. Role of the domestic chicken (Gallus gallus) in the epidemiology of urban visceral leishmaniasis in Brazil. Emerg Infect Dis. 2002;8(12):1480-5.

39. Adler GH, Becerra MT, Travi BL. Feeding success of Lutzomyia evansi (Diptera: Psychodidae) experimentally exposed to small mammal hosts in an endemic focus of Leishmania chagasi in northern Colombia. Biomedica. 2003;23(4):396-400.

40. Zulueta AM, Villarroel E, Rodriguez N, Feliciangeli MD, Mazzarri M, Reyes O, et al. Epidemiologic aspects of American visceral leishmaniasis in an endemic focus in Eastern Venezuela. Am J Trop Med Hyg. 1999;61(6):945-50.

41. Macedo-Silva VP, Martins DR, De Queiroz PV, Pinheiro MP, Freire CC, Queiroz JW, et al. Feeding preferences of Lutzomyia longipalpis (Diptera: Psychodidae), the sand fly vector, for Leishmania infantum (Kinetoplastida: Trypanosomatidae). J Med Entomol. 2014;51(1):237-44.

42. Sales KG, Costa PL, de Morais RC, Otranto D, Brandao-Filho SP, Cavalcanti Mde $P$, et al. Identification of phlebotomine sand fly blood meals by realtime PCR. Parasit Vectors. 2015;8:230.

43. Anaguano DF, Ponce P, Baldeon ME, Santander S, Cevallos V. Blood-meal identification in phlebotomine sand flies (Diptera: Psychodidae) from Valle Hermoso, a high prevalence zone for cutaneous leishmaniasis in Ecuador. Acta Trop. 2015;152:116-20.

44. Kumar NP, Srinivasan R, Jambulingam P. DNA barcoding for identification of sand flies (Diptera: Psychodidae) in India. Mol Ecol Resour. 2012;12(3):414-20.

45. Hoyos RUS, Velez ID. Tipificacion de especımenes colombianos de Lutzomyia longipalpis (Diptera: Psychodidae) mediante "Codigo de Barras". Rev Col Entomol. 2012;38:134-40.
46. Florin DA, Davies SJ, Olsen C, Lawyer P, Lipnick R, Schultz G, et al. Morphometric and molecular analyses of the sand fly species Lutzomyia shannoni (Diptera: Psychodidae: Phlebotominae) collected from seven different geographical areas in the southeastern United States. J Med Entomol. 2011;48(2):154-66.

47. Perez-Doria A, Bejarano EE, Sierra D, Velez ID. Molecular evidence confirms the taxonomic separation of Lutzomyia tihuiliensis from Lutzomyia pia (Diptera: Psychodidae) and the usefulness of pleural pigmentation patterns in species identification. J Med Entomol. 2008;45(4):653-9.

48. Contreras Gutierrez MA, Vivero RJ, Velez ID, Porter CH, Uribe SDNA. Barcoding for the identification of sand fly species (Diptera, Psychodidae, Phlebotominae) in Colombia. PLoS One. 2014;9(1):e85496.

49. Lunt DH, Zhang DX, Szymura JM, Hewitt GM. The insect cytochrome oxidase I gene: evolutionary patterns and conserved primers for phylogenetic studies. Insect Mol Biol. 1996;5(3):153-65.

50. Hebert PD, Cywinska A, Ball SL, deWaard JR. Biological identifications through DNA barcodes. Proc Biol Sci. 2003;270(1512):313-21.

51. Lins RM, Souza NA, Peixoto AA. Genetic divergence between two sympatric species of the Lutzomyia longipalpis complex in the paralytic gene, a locus associated with insecticide resistance and lovesong production. Mem Inst Oswaldo Cruz. 2008;103(7):736-40.

52. Santos MF, Ribolla PE, Alonso DP, Andrade-Filho JD, Casaril AE, Ferreira AM, et al. Genetic structure of Lutzomyia longipalpis populations in Mato Grosso Do Sul, Brazil, based on microsatellite markers. PLoS One. 2013;8(9):e74268.

53. Mutebi J, Tripet F, Alexander JB, Lanzaro GC. Genetic differentiation among populations of Lutzomyia longipalpis (Diptera: Psychodidae) in Central and South America. Ann Entomol Soc Amer. 2002;95(6):740-52.

\section{Submit your next manuscript to BioMed Central and we will help you at every step:}

- We accept pre-submission inquiries

- Our selector tool helps you to find the most relevant journal

- We provide round the clock customer support

- Convenient online submission

- Thorough peer review

- Inclusion in PubMed and all major indexing services

- Maximum visibility for your research

Submit your manuscript at www.biomedcentral.com/submit
C Biomed Central 